\title{
Maternal health and human rights
}

\section{Ymkje E Ratsma ${ }^{1}$, Joyce Malongo ${ }^{2}$}

1. Zonal Health Support Office (South-East), Ministry of Health, Malawi

2. Centre for Human Rights and Rehabilitation, Lilongwe, Malawi Correspondence: Dr. YEC Ratsma P.O. Box 216, Zomba, Malawi yecratsma@gmail.com

\begin{abstract}
In Malawi the maternal mortality ratio is extremely high. Since almost all maternal deaths are avoidable, maternal mortality is also an issue of human rights. This paper examines the root causes of high maternal mortality in Malawi and applies a human rights-based approach to the reduction of maternal mortality. It recommends roles for the various duty-bearers. It describes indicators to monitor and evaluate the strategy and suggests how transparency and accountability should be ensured. In conclusion, full and effective implementation of the strategy is indispensable for achieving the fifth Millennium Development Goal that calls for the reduction of maternal mortality.
\end{abstract}

\section{Introduction}

Achieving the fifth Millennium Development Goal by reducing maternal mortality and morbidity remains a great challenge for many low-resourced countries, particularly in sub-Saharan Africa. In Malawi the maternal mortality ratio is extremely high: 984 per 100,000 live births according to the Malawi Demographic and Health Survey (2004) ${ }^{1}$ versus 807 per 100,000 live births according to the Multiple Indicator Cluster Survey $(2006)^{2}$. However, the implied reduction from 984 in one survey to 807 in the other is not statistically significant ${ }^{2}$. The main direct obstetric causes of maternal mortality are puerperal sepsis, obstructed labour and ruptured uterus, haemorrhage, complications of abortion, and eclampsia, whilst the main indirect causes of maternal mortality are HIV/AIDS and anaemia ${ }^{3}$. Access to skilled attendance at birth, emergency obstetric care, contraception, safe abortion services and comprehensive post-abortion care are key to reducing maternal mortality. However, although achieving the goal depends on increasing access to key technical interventions, simply identifying those interventions and calling for their broad deployment is not enough ${ }^{4}$. Strengthening of health systems is important to render these strategies effective. But more needs to be done. In addition to the direct obstetric and indirect causes there are many underlying factors that contribute to high maternal mortality in developing countries.

Since almost all maternal deaths are avoidable, maternal mortality is also an issue of human rights. Human rights are universal legal guarantees protecting individuals and groups against actions that interfere with fundamental freedoms and human dignity. They are international standards that have been negotiated and accepted by governments as binding upon them and in their countries ${ }^{5}$. They provide a legal and ethical framework for governments, communities and individuals. They set the standard against which to evaluate actions ${ }^{5}$. The Universal Declaration of Human Rights adopted by the UN General Assembly in 1948 states that 'All human beings are born free and equal in dignity and rights'. The International Covenant on Economic, Social and Cultural Rights in 1966 states that every person has 'the right to the highest attainable standard of physical and mental health'. Malawi ratified the Convention on the Elimination of All Forms of Discrimination Against Women (CEDAW) in 1987. CEDAW is the only human rights treaty that affirms the reproductive rights of women. In 1994, the International Conference on Population and Development in Cairo clarified the concepts of women's empowerment, gender equity, and reproductive health and rights. However, despite these international agreements over half a million women continue to die globally each year from pregnancy and childbirth-related causes.

This paper examines the root causes of high maternal mortality in Malawi and applies a human rights-based approach to the reduction of maternal mortality. This approach has the following elements: inclusion and nondiscrimination; participation and empowerment of rightsholders; holding duty-bearers accountable for fulfilling their obligations to respect, protect and guarantee rights; and progressive realisation of the right to health.

\section{Causality analysis}

The root causes of high maternal mortality in Malawi are gender discrimination, poverty, lack of education, an inadequate health system and restrictive abortion legislation. Each of these factors is examined in detail as follows:

\section{- Gender discrimination:}

There is persistence of customary law discriminatory towards women that is permissive of violence against women and girls ${ }^{6}$. Malawi has deep-rooted cultural norms, customs and traditions including forced and early marriage perpetuating gender discrimination ${ }^{6}$. These practices constitute serious obstacles to the realization of good maternal health. The low status of women in society and their dependency on others, financially and in decisionmaking, undermine their autonomy and negatively affect their ability to access essential maternal health services. There is a direct link between harmful traditional practices and the spread of $\mathrm{HIV} / \mathrm{AIDS}^{6}$, which is a major cause of indirect maternal mortality.

\section{- Poverty:}

A significant part of the population in Malawi is poor: about $60 \%$ of the population lives in absolute poverty (below $\$ 1$ per day) ${ }^{7}$. Many rural women experience precarious living conditions ${ }^{6}$ and a large proportion of them are not able to access emergency obstetric care in time, because they lack enough resources e.g. for transport (despite public hospitals providing free maternal health services).

\section{- Lack of education:}

Education empowers women to better judge a health problem, to make their own decisions, to be economically independent and to be able to access health care. Lack of education is associated with poor health-related and health-seeking behaviour and may result in poor health status. Overall, $69 \%$ of adults in Malawi are literate; $77 \%$ of men compared to $67 \%$ 
of women. Urban respondents have a higher level of literacy (86\% for men and $85 \%$ for women) than rural respondents $(75 \% \text { for men and } 63 \% \text { for women })^{2}$. There is a high drop-out rate of girls due to early and forced marriage, and teenage pregnancy. More boys $(73 \%)$ than girls $(68 \%)$ reach grade 8 of primary school $^{2}$. Girls have low enrolment rates in higher education. There is lack of sex education for both girls and boys ${ }^{6}$.

\section{- Inadequate health system:}

There is low availability and accessibility of family planning and perinatal care, particularly in rural areas ${ }^{6}$. Health providers have attitude problems and the sexual and reproductive health care services suffer from low quality.

\section{- Restrictive abortion legislation:}

There is a high incidence of maternal morbidity and mortality as a result of unsafe abortions.

\section{Role, obligation and capacity gap analyses}

Human rights primarily determine the relationship between individuals and groups with valid claims (rights-holders) and state actors with corresponding obligations (duty-bearers). Governments have three levels of obligation: to respect, to protect and to fulfil human rights. Capacity gap analysis looks at the capacities of the rights-holders to claim their rights and of the duty-bearers to meet their obligations, especially with regard to the root causes identified.

\section{Rights-holders}

The main rights-holders are women and girls. Poor women are most affected by poor maternal health. The rights-holders are lacking empowerment to claim their right to quality maternal health services. They also lack knowledge on good maternal health practices and on their right to be protected from harmful practices, i.e. civic education is not adequate.

\section{Duty-bearers}

The primary duty-bearer is the State (Ministry of Health, Ministry of Finance and other Ministries). Other duty-bearers are the World Health Organisation (WHO), United Nations agencies, development partners, professional councils, training institutions and the Christian Health Association of Malawi (CHAM). Health care providers are duty-bearers at health facility level and community and religious leaders at community level.

\section{Strategy}

The challenge of a human rights declaration is how to implement and translate it into action to protect and promote human rights. A human rights-based approach encourages rights-holders to claim their rights and develops the capacity of duty-bearers to meet their obligations. This paper recommends the following roles for the various dutybearers:

\section{Government}

- Formulate and implement relevant policies and strategies for the reduction of maternal mortality including gender- and rights-based approach in all maternal health care services.

- Introduce legislation to ensure that violence against women and girls constitutes a criminal offence, so that traditional courts no longer apply customary law that is discriminatory towards women ${ }^{6}$.

- Strengthen the district health system with priority given to sexual and reproductive health services.

- Institute policies and programmes that prioritise measures that promote universal access to high quality emergency obstetric care services ${ }^{5}$.

- Ensure that women have access to contraceptive counselling and methods, to safe termination of pregnancy and to quality services for the management of complications arising from abortion. Access to safe, legal abortion on request improves maternal health and prevents maternal deaths ${ }^{4}$.

- Implement sex education for girls and boys, with special attention paid to the prevention of early pregnancy and the control of sexually transmitted infections and HIV/ AIDS $^{6}$.

- Increase number of service level agreements with CHAM to ensure free access to essential maternal health services. A service level agreement is a contractual arrangement between government and CHAM aiming at accessible and affordable essential health services' delivery for the poor, whereby the government is the contractor who pays for the services provided free of charge by CHAM.

\section{Health care providers}

- Treat men as well as women with respect, ensure confidentiality and privacy, respect women's autonomy to decide on their own health and provide information and services to everybody who needs them and avoid discrimination based on gender, social class, marital status or age.

- Provide sexual and reproductive health services to adolescents that are sensitive to their vulnerabilities and designed to meet their needs ${ }^{4}$.

\section{Non-governmental and civil society organisations}

- Provide civic education to communities with emphasis on right to (maternal) health. Sensitise women and girls on the importance of giving birth at a registered health facility as opposed to delivery by traditional birth attendants.

- Advocate for an increase in resources addressing maternal health services in the national budget. Beyond government, advocacy should also be carried out to international organizations to put maternal health as a priority among the other health issues they are supporting. Hereby it should be taken into account that for an impact to be made on the maternal mortality ratio at least ten years of sustained improved service delivery is required ${ }^{8}$.

\section{Professional councils and training institutions}

- Reinforce professional conduct to ensure provision of quality maternal health care.

- Integrate human rights and medical ethics into the training curricula.

\section{Community}

- Community and religious leaders have an obligation to prevent social and religious customs and practices that lead to exclusion or discrimination of women or even 
sexual or gender-based violence.

\section{Monitoring}

There is a need to develop indicators and set targets to monitor and evaluate the implementation of the strategy. The UN Millennium Project recommends that the maternal health targets should be equity-sensitive ${ }^{4}$. There are three types of indicators:

\section{Structural indicators}

Have relevant laws, policies and strategies been put in place for the reduction of maternal mortality? Have gender- and rights-based approaches been included in these?

\section{Process indicators}

The national Health Management Information System contains process indicators that measure access to skilled birth attendance and emergency obstetric care. There is a need for additional process indicators that relate to the strategy components on civic education to communities and sex education for girls and boys (e.g. number of schools providing sexual and reproductive health education).

\section{Outcome indicators}

The Malawi Demographic and Health Survey ${ }^{1}$ and Multiple Indicator Cluster Survey ${ }^{2}$ collect data on the maternal mortality ratio (using the direct sisterhood method) and neonatal mortality rate. From a human rights-based perspective it is important to disaggregate these data in order to measure the reduction of maternal mortality among different social groups (e.g. poor women, rural women). District Health Offices conduct maternal death reviews that yield important information regarding avoidable factors and substandard care so that health system improvements can be made.

Ministry of Health should coordinate and support monitoring and evaluation of progress on the implementation of the Road Map for accelerating the reduction of Maternal and Neonatal Mortality and Morbidity in Malawi 2005-2010'. UN Agencies and development partners should support the monitoring of the Road Map.

\section{Transparency and accountability}

Transparency and accountability will be ensured by the involvement of both the rights- holders and duty-bearers in planning, implementation, monitoring and evaluation of the strategy. Although it is the prime responsibility of the state to ensure that all human rights standards and key principles are respected during the design and implementation of the strategy, there is also an important role for civil society organisations such as the White Ribbon Alliance and Malawi Health Equity Network to act as human rights watch. The State should seek support from, and continue to work in close cooperation with appropriate international agencies such as WHO, UNFPA and UNICEF. The state needs to coordinate and collaborate effectively with non-governmental and women's organizations. Full and effective implementation of the strategy is indispensable for achieving the fifth Millennium Development Goal that calls for the reduction of maternal mortality.

\section{Acknowledgments}

The authors would like to thank Ms Bridget Lehuray and Dr Jan Hofman for reviewing and commenting on an earlier draft of this article.

\section{References}

1. Malawi Demographic and Health Survey 2004, NSO, Zomba, Malawi.

2. Multiple Indicator Cluster Survey 2006, NSO, Zomba, Malawi.

3. Ratsma YEC, Lungu K, Hofman JJ, White SA. Confidential enquiries into institutional maternal deaths in the southern region of Malawi 2001. Malawi Medical Journal 2006; 17(3), 75-80.

4. UN Millennium Project 2005. Who's got the Power? Transforming Health Systems for Women and Children. Summary version of the report of the Task Force on Child Health and Maternal Health. New York, USA.

5. Freedman LP. Using human rights in maternal mortality programs: from analysis to strategy. Int J Gynecol Obstet 2001; 75, 51-60.

6. Concluding comments of the Committee on the Elimination of Discrimination against Women: Malawi. Thirty-fifth session. 15 May - 2 June 2006.

7. Welfare Monitoring Survey 2007, NSO, Zomba, Malawi.

8. Output to Purpose Review of the Safe Motherhood Project, Malawi. December 2003.

9. Road Map for accelerating the reduction of Maternal and Neonatal Mortality and Morbidity in Malawi 2005-2010. Third revised version. March 2007. 